\title{
Silent Corticotroph Tumor with Adrenocortical Choristoma in an Eleven-year-old Boy
}

\author{
(D) Hande Turan', (D) Gürkan Tarçın', (D) Özgür Mete ${ }^{2}$, (D) Ada Bulut Sinoplu³, (D) Saadet Olcay Evliyaoğlu', (D) Büge Öz4, (DD Oya Ercan' \\ 1 University of Health Sciences Turkey, Istanbul University-Cerrahpaşa, Cerrahpaşa Faculty of Medicine, Department of Pediatric Endocrinology, \\ istanbul, Turkey \\ 2University of Toronto, Department of Laboratory Medicine and Pathobiology, Toronto, Canada; University Health Network, Department of \\ Pathology, Toronto, Canada \\ 3 University of Health Sciences Turkey, Istanbul University-Cerrahpaşa, Cerrahpaşa Faculty of Medicine, Department of Pediatrics, istanbul, Turkey \\ 4 University of Health Sciences Turkey, İstanbul University-Cerrahpaşa, Cerrahpaşa Faculty of Medicine, Department of Pathology, istanbul, Turkey
}

\section{What is already known on this topic?}

Silent corticotroph adenomas (SCAs) do not manifest biochemical or clinical evidence of hypercortisolism, but are histologically immunopositive for adrenocorticotrophic hormone (ACTH) and Tpit, the transcription factor for functioning and SCAs, which is useful in diagnosis of corticotroph and null cell adenoma. The existence of adrenocortical cells within the pituitary gland, which can be explained as a choristoma, is a very rare entity, and the co-occurrence of these two entities have only been reported in few cases.

\section{What this study adds?}

Adrenocortical choristoma in SCA is a very rare entity, and herein, to the best of our knowledge, we describe the fourth and the youngest patient reported to date.

\begin{abstract}
Silent corticotroph tumors are composed of corticotroph cells, but do not manifest any biochemical or clinical evidence of hypercortisolism. A choristoma is a benign, congenital proliferation of histologically mature tissue elements normally not present at the site of occurrence. The existence of adrenocortical cells within the pituitary gland, which can be explained as a choristoma, is a very rare entity, and the co-occurrence of these two entities have only been reported in few cases. We report an 11-year-old boy with central hypothyroidism. On cranial magnetic resonance imaging a pituitary tumor was detected, and histopathological studies led to a diagnosis of an adrenal choristoma and a silent corticotroph tumor in the pituitary gland. The presence of adrenocortical cells were confirmed by positive calretinin, inhibin and Melan A staining, and the corticotroph cells by immunohistochemistry demonstrating adrenocorticotropic hormone positivity. Herein, we report the fourth and the youngest case of silent corticotroph tumor with adrenocortical choristoma in the literature. Even though the underlying mechanism is not fully understood, suggested mechanisms are discussed.
\end{abstract}

Keywords: Adrenocortical choristoma, corticotroph adenoma, steroidogenic factor 1

\section{Introduction}

Corticotroph adenomas (CAs) comprise approximately $10 \%$ of all pituitary tumors (1). Functional CAs are associated with elevated circulating adrenocorticotropic hormone (ACTH) and cortisol levels leading to Cushing disease, with features of hypercortisolism or Nelson's syndrome (2). Up to $20 \%$ of CAs are described as silent corticotroph adenomas (SCAs), and they do not manifest biochemical or clinical evidence of hypercortisolism, whereas both silent and functional CAs are immunopositive for ACTH and Tpit, the transcription factor for functioning and SCAs, which is useful in diagnosis of CAs and null cell adenoma $(3,4,5)$. SCAs comprise a very small proportion of the total population of nonfunctional pituitary adenomas. Despite being silent, they show aggressive behavior (6).
Address for Correspondence: Hande Turan MD, University of Health Sciences Turkey, İstanbul UniversityCerrahpaşa, Cerrahpaşa Faculty of Medicine, Department of Pediatric Endocrinology, İstanbul, Turkey Phone: +90 5059113735 E-mail: dr.handeerdogan@gmail.com ORCID: orcid.org/0000-0003-0121-3756

${ }^{\circ}$ Copyright 2022 by Turkish Pediatric Endocrinology and Diabetes Society

The Journal of Clinical Research in Pediatric Endocrinology published by Galenos Publishing House.
Conflict of interest: None declared Received: 12.11 .2020 Accepted: 09.02.2021 
A choristoma is a benign, congenital proliferation of histologically mature tissue elements normally not present at the site of occurrence. This heterotopic congenital mass results from normal tissue elements migrating to or remaining in an abnormal location during embryogenesis. Adrenocortical choristomas have been identified in a wide variety of other non-steroidogenic tissues, including kidney, lung, spinal canal and the leptomeningeal surface in the cranium $(7,8)$. However only four previous reports have described the occurrence of interspersed adrenal cortical cells in three SCAs and in one clinically functioning CA $(7,9,10,11)$.

SCAs are diagnosed incidentally or when they reach a size which leads to clinical symptoms because of mass effects, such as headache or compression findings (1). Adrenocortical choristoma in SCA is a very rare entity, and herein, to our knowledge, we describe only the fourth and the youngest patient reported to date, who was diagnosed during evaluation of central hypothyroidism.

\section{Case Report}

The patient had been on regular follow-up in our clinic with a diagnosis of compensated hypothyroidism due to an exaggerated thyroid-stimulating hormone (TSH) response to thyrotropin-releasing hormone and had been on L-thyroxine treatment since four months of age. The patient did not have any relevant past medical and familial history, except for the presence of double urethral meatus. At 11 years of age, despite L-thyroxine treatment, findings compatible with central hypothyroidism (free thyroxine: $0.78 \mathrm{ng} / \mathrm{dL}$, normal range: $0.98-1.63$ and TSH: $0.47 \mathrm{mIU} / \mathrm{mL}$, normal range: 0.51-4.3) were noted. On physical examination, he was in the $90-97^{\text {th }}$ percentile for weight and $90^{\text {th }}$ percentile for height. His blood pressure was normal $(90 / 50 \mathrm{mmHg}$, 50$75^{\text {th }}$ percentile). All other pituitary hormones were found to be within normal ranges. Cortisol was found to be low (4.82 ug/dL, normal: > $15 \mathrm{ug} / \mathrm{dL}$ ), and ACTH level was $17.3 \mathrm{pg} /$ $\mathrm{mL}$ (relatively low). An ACTH deficiency was confirmed with a peak cortisol of $15.27 \mathrm{ug} / \mathrm{dL}$ (normal $>18 \mathrm{ug} / \mathrm{dL}$ ) to low dose ACTH stimulation test (12). Thus, cortisol replacement was added to L-thyroxine replacement.

Magnetic resonance imaging (MRI) identified a tumor measuring $11 \times 11 \times 10 \mathrm{~mm}$ in the pituitary region with enhancement characteristics suggestive of a pituitary adenoma (also known as pituitary neuroendocrine tumor) (Figure 1). Transsphenoidal resection of the pituitary tumor was performed due to the tumor mass effect which resulted in central hypothyroidism and central adrenal insufficiency. Pathological examination identified a CA with adrenocortical choristoma. Growth failure was evident after surgery (Figure 2). Based on growth hormone $(\mathrm{GH})$ stimulation tests, complete GH deficiency was confirmed, and GH therapy was initiated. The patient benefited from the treatment with a height velocity of $8.4 \mathrm{~cm} / \mathrm{year}$ in the first year, and his pubertal development progressed in accordance with his age.

Six years after surgery, tumoral recurrence was observed on MRI in the pituitary gland, with a microadenoma of 5 $\mathrm{mm}$ in diameter. However, since the tumor did not cause any clinical findings, the patient was followed up with MRI repeated at 6-month intervals.

Beforehand, informed consent was obtained from the parents of the patient for all steps of treatment and added to the patient's file.

\section{Histopathological Evaluation}

Histopathological evaluation of the tumor revealed the presence of two groups of cells. These were small round cells with amphophilic to basophilic cytoplasm and large spherical, oval cells with abundant, granular, partly vacuolated acidophilic cytoplasm (Figure 3A, 3B).

By immunohistochemistry, the small cells were immunopositive for ACTH and synaptophysin. In addition, these cells were diffusely positive for Periodic Acid-Schiff (PAS), indicating the presence of corticotroph cells with a predominant dense granulation pattern. The larger cells were immunonegative for synaptophysin (Figure 4A, 4B) but positive for mitochondrial antigen, inhibin (Figure 5A, 5B), calretinin and Melan A (clone A103). The cells were rich in mitochondria, and did not stain with PAS, compatible with adrenocortical tissue.

The ratio of the two cell types varied considerably from area to area. Major cellular or nuclear pleomorphism was not noted, and no mitotic figures were seen in either component. The Ki67 labeling index was 3-4\%. However,

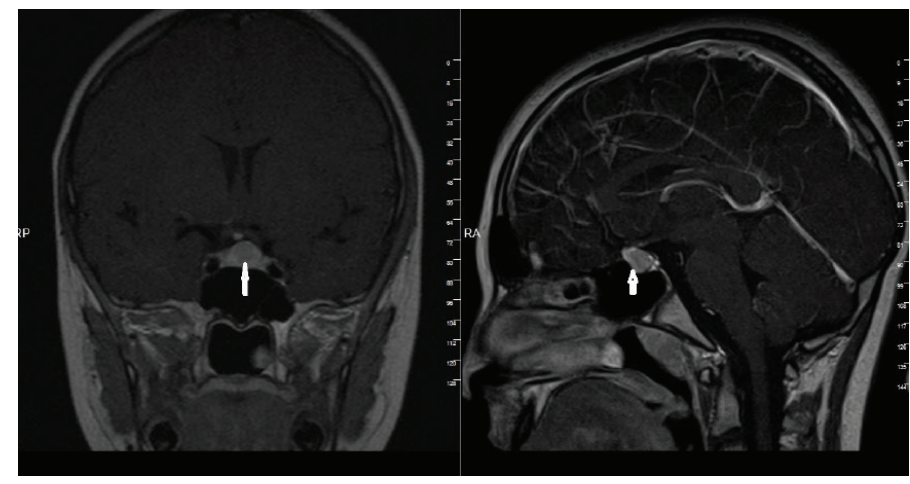

Figure 1. Magnetic resonance imaging of the pituitary gland at eleven years of age. The $1 \mathrm{~cm}$ adenoma is marked with an arrow 
the tumor margins could not be confirmed due to the nature of the specimen excision.

\section{Discussion}

SCAs comprise $3-19 \%$ of nonfunctional pituitary adenomas (1). The most frequently reported presenting features of SCAs are tumor mass effects, including headaches, visual disturbance, and hypopituitarism (13). Central hypothyroidism and central adrenal insufficiency developed during the follow-up of our patient. GH deficiency emerged after surgery, as an expected complication of pituitary surgeries (14).

It has been demonstrated that SCAs can be more aggressive than any other clinically nonfunctioning adenomas with a higher prevalence of cavernous sinus invasion and a higher rate of recurrence $(5,13)$. In the other three case reports
$(7,10,11)$, data with regard to postoperative follow-up period were lacking, but the tumor in our patient recurred after six years.

The SCA in our patient was associated with adrenocortical cells. Co-existence of CA with adrenocortical choristoma is a very rare entity. In 1996, Oka et al (7) were the first to report such a tumor in a 16-year-old boy who presented with growth retardation (7). Three of the previously described tumors, including the patient reported by Oka et al (7) were all biochemically silent, but the fourth one showed evidence of function (9). Similar to our case, all four previously reported tumors were macroadenomas (tumors exceeding $1.0 \mathrm{~cm}$ on MRI studies). Three of the four cases were diagnosed in the teenage period (16-18 years of age), while only one was adult (11). Our 11-year-old patient was the youngest case reported to date.

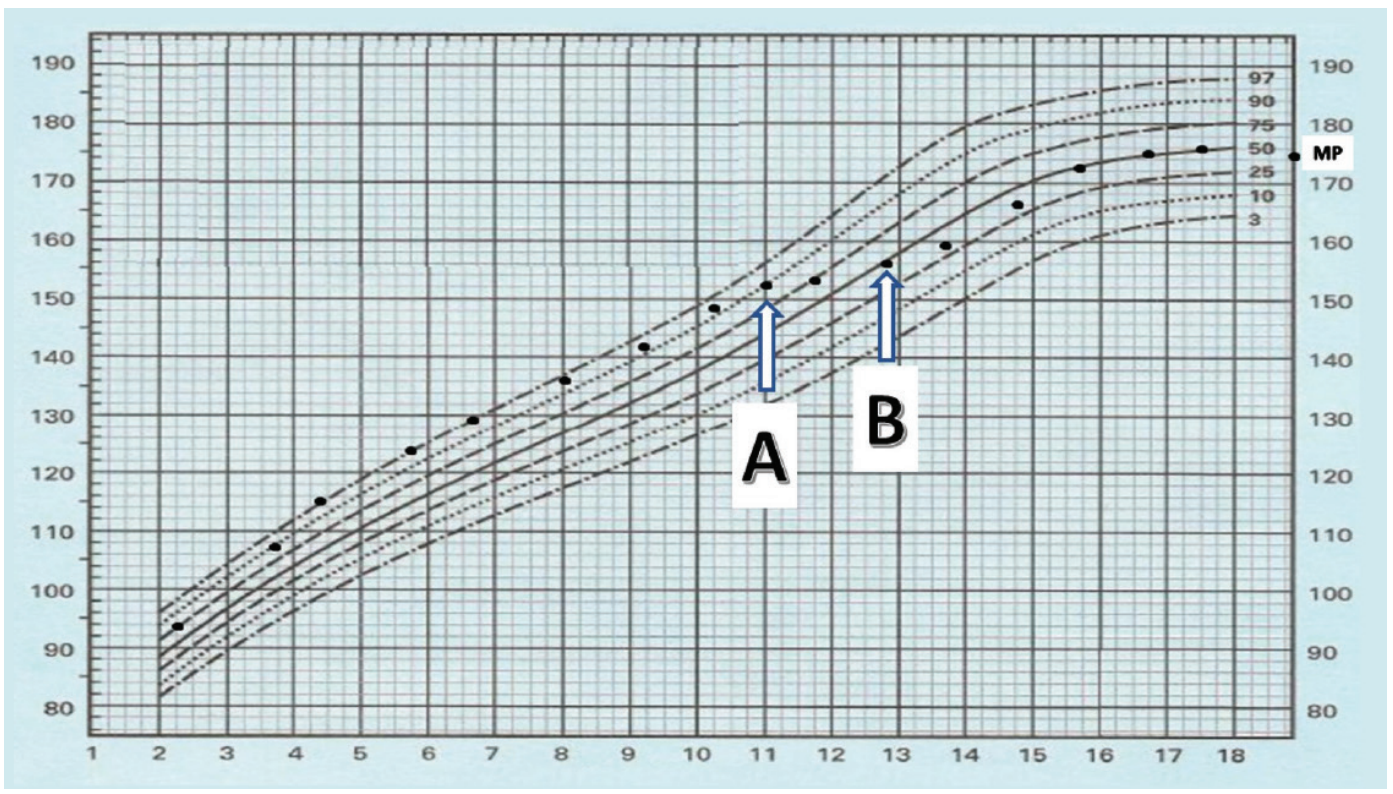

Figure 2. Percentile curve of the case. A) Pituitary surgery; B) Initiation of the growth hormone therapy MP: midparental height
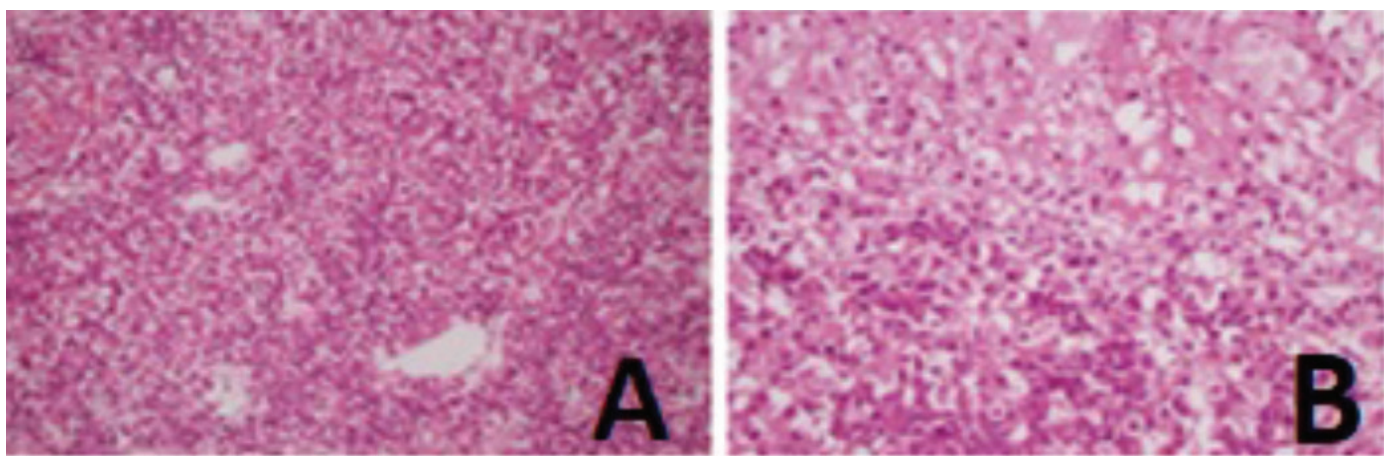

Figure 3. A, B) Mixture of the small, round, well-granulated cells with amphophilic or basophilic cytoplasm (corticotroph cells) and the large spherical or oval cells with abundant, granular, partly vacuolated cytoplasm (adrenocortical cells) form groups (H\&E; magnification x100-400) 


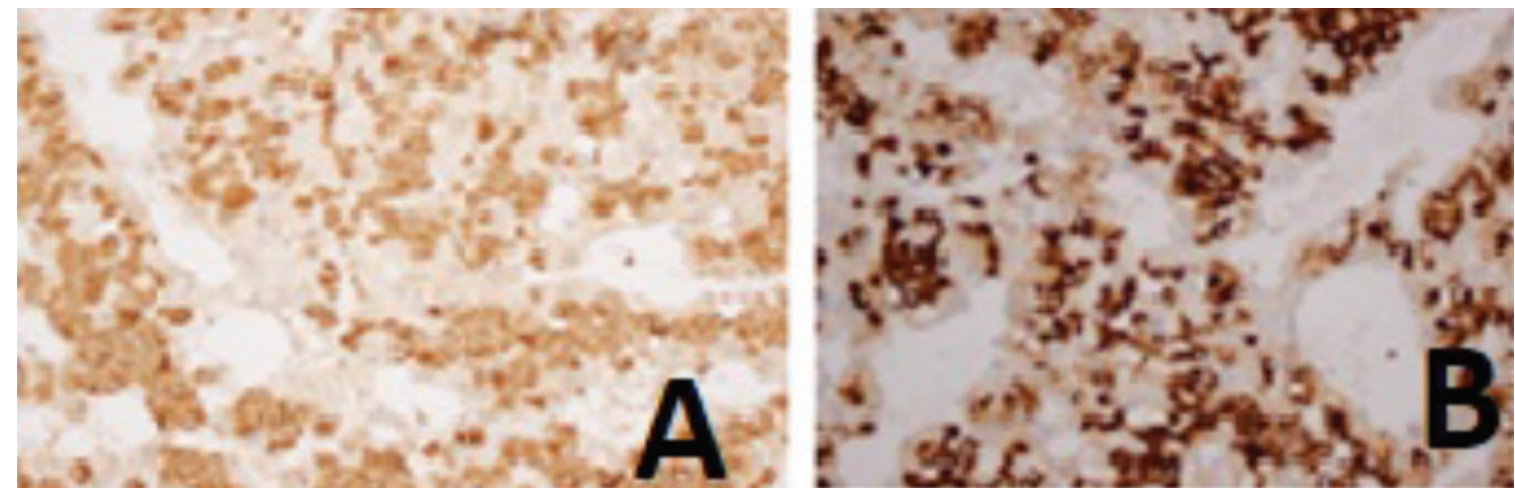

Figure 4. A) Small cells immunopositive for adrenocorticotrophic hormone (adrenocorticotrophic hormone; magnification x400). B) Adrenocortical cells are immunonegative and corticotroph cells immunpositive for synaptophysin (synaptophysin; magnification $\mathrm{x} 400)$
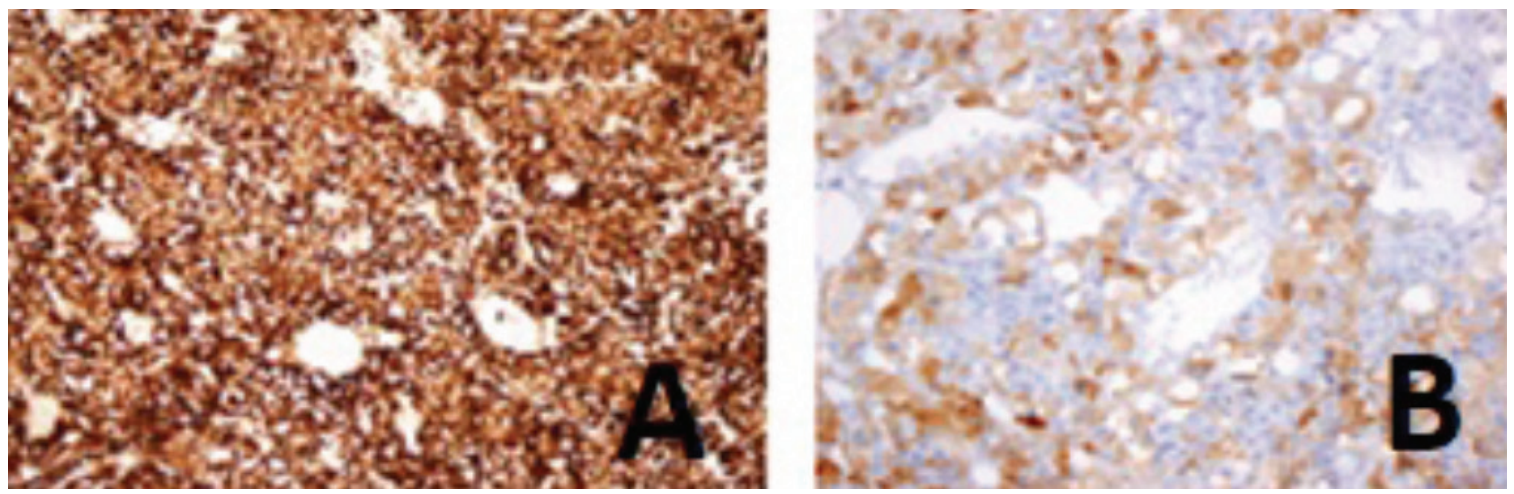

Figure 5. A) Large adrenocortical cells with vacuolated cytoplasm are densely immunpositive for mitochondrial antigen (mitochondrial ag; magnification x100). B) Adrenocortical cells are immunpositive for inhibin (inhibin; magnification x400)

The adult patient was a 35-year-old male patient, and he had secondary hypothyroidism, hypogonadotropic hypogonadism and "low insulin-like growth factor-1 with growth hormone" (11). The other three teen-aged patients had either growth retardation (basal $\mathrm{GH}$ and insulin-like growth factor-1 levels were reported to be low) or delayed pubertal development. However, our patient had a diagnosis of central hypothyroidism and ACTH insufficiency, which may be associated with the compression due to the tumor that resulted in selective adenohypophyseal dysfunction. Coversely, in a silent adenoma, endocrine hypoactivity may be due to defective production, packaging or release of hormones by pituitary cells. In our case growth retardation developed later during follow-up, and GH deficiency was confirmed. Pubertal development progressed in accordance with age and thus he did not have hypogonadotropic hypogonadism.

The origin of adrenocortical cells in CAs and the reason for co-existence with corticotroph cells is not clearly understood. It is suggested that they might be a random mixture of the two types of cells proliferating in the sella (15). As discussed in previous reports, there might be two explanations for the existence of the two cell types together. The first one is that adrenocortical cells might have differentiated from stem cells, such as undifferentiated mesenchymal cells, under prolonged ACTH stimulation. Studies in humans and in experimental animals support the hypothesis that ACTH stimulation in CAs converts mesenchymal cells to adrenocortical-like cells (16). Groat (16) observed differentiation of the adrenocortical-like cells from ovarian and other mesenchymal tissues in adrenalectomized ground-squirrels. It was also suggested that these two cell types might interact in a paracrine manner due to the close relationship between ACTH and adrenocortical cells. However, our patient had ACTH deficiency which makes this mechanism unlikely. Mete et al (11) suggested that steroidogenic factor-1, which is present in both pituitary and adrenal cortex, may have an important role in the proliferation and differentiation of uncommitted mesenchymal stem cells within the sella. The second explanation is that the adrenocortical cells may have migrated to the wrong place in early embryonic development $(7,8,10)$. In the present case, the latter explanation appears to be more likely. 


\section{Conclusion}

The lack of biochemical and clinical evidence of Cushing syndrome, despite corticotroph tumor, indicated the presence of a SCA. In our patient, the presence of the second group of cells, similar to adrenocortical cells in this heterotopic location is compatible with choristoma. The younger age of our patient than previously reported cases and clinical significance of SCA, make this case remarkable, and the recurrence of the tumor in the present case after surgery also makes this case report unique. Another point of note is that endocrinologists should not ignore unexpectedly suppressed TSH values while evaluating thyroid function tests during the follow-up of the patients with primary hypothyroidism and should be careful in terms of newly developing central hypothyroidism. In such a situation, we suggest that other pituitary hormone levels should be measured and pituitary imaging should be undertaken.

\section{Ethics}

Informed Consent: Consent form was filled out by all participants.

Peer-review: Externally peer-reviewed.

\section{Authorship Contributions}

Surgical and Medical Practices: Özgür Mete, Büge Öz, Concept: Hande Turan, Ada Bulut Sinoplu, Oya Ercan, Design: Hande Turan, Oya Ercan, Data Collection or Processing: Hande Turan, Gürkan Tarçın, Özgür Mete, Ada Bulut Sinoplu, Oya Ercan, Analysis or Interpretation: Hande Turan, Oya Ercan, Literature Search: Hande Turan, Gürkan Tarçın, Oya Ercan, Writing: Hande Turan, Gürkan Tarçın, Özgür Mete, Saadet Olcay Evliyaoğlu, Büge Öz, Oya Ercan.

Financial Disclosure: The authors declared that this study received no financial support.

\section{References}

1. Cooper O. Silent corticotroph adenomas. Pituitary 2015;18:225-231.

2. Melmed S. Mechanisms for pituitary tumorigenesis: the plastic pituitary. J Clin Invest 2003;112:1603-1618.
3. Asa SL, Mete O. Immunohistochemical Biomarkers in Pituitary Pathology. Endocr Pathol 2018;29:130-136.

4. Mete O, Asa SL. Structure, Function, and Morphology in the Classification of Pituitary Neuroendocrine Tumors: the Importance of Routine Analysis of Pituitary Transcription Factors. Endocr Pathol 2020;31:330-336. Epub 2020 Aug 19

5. Alahmadi H, Lee D, Wilson JR, Hayhurst C, Mete O, Gentili F, Asa SL, Zadeh G. Clinical features of silent corticotroph adenomas. Acta Neurochir (Wien) 2012;154:1493-1498. Epub 2012 May 24

6. Drummond J, Roncaroli F, Grossman AB, Korbonits M. Clinical and Pathological Aspects of Silent Pituitary Adenomas. J Clin Endocrinol Metab 2019;104:2473-2489.

7. Oka H, Kameya T, Sasano H, Aiba M, Kovacs K, Horvath E, Yokota Y, Kawano N, Yada K. Pituitary choristoma composed of corticotrophs and adrenocortical cells in the sella turcica. Virchows Arch 1996;427:613617.

8. Wiener MF, Daalgaard SA. Intracranial adrenal gland; a case report. AMA Arch Pathol 1959;67:228-233.

9. Albuquerque FC, Weiss MH, Kovacs K, Horvath E, Sasano H, Hinton DR. A Functioning Composite "Corticotroph" Pituitary Adenoma with Interspersed Adrenocortical Cells. Pituitary 1999;1:279-284.

10. Coiré CI, Horvath E, Kovacs K, Smyth HS, Sasano H, Iino K, Feig DS. A Composite Silent Corticotroph Pituitary Adenoma with Interspersed Adrenocortical Cells: Case Report Neurosurgery 1998;42:650-654.

11. Mete O, Ng T, Christie-David D, McMaster J, Asa SL. Silent Corticotroph Adenoma with Adrenal Cortical Choristoma: a Rare but Distinct Morphological Entity. Endocrine Pathol 2013;24:162-166.

12. El-Farhan N, Pickett A, Ducroq D, Bailey C, Mitchem K, Morgan N, Armston A, Jones L, Evans C, Rees DA. Method-specific serum cortisol responses to the adrenocorticotrophin test: comparison of gas chromatography-mass spectrometry and five automated immunoassays. Clin Endocrinol (Oxf) 2013;78:673-680.

13. Scheithauer BW, Jaap AJ, Horvath E, Kovacs K, Lloyd RV, Meyer FB, Laws ER Jr, Young WF Jr. Clinically Silent Corticotroph Tumors of the Pituitary Gland. Neurosurgery 2000;47:723-730.

14. Kobayashi N, Yamaguchi-Okada M, Horiguchi K, Fukuhara N, Nishioka $\mathrm{H}$, Yamada S. Postoperative growth hormone dynamics in clinically nonfunctioning pituitary adenoma. Endocr J 2018;65:827-832.

15. Larkin S, Ansorge O. Development And Microscopic Anatomy of The Pituitary Gland. In: De Groot LJ, Chrousos G, Dungan K, Feingold KR, Grossman A, Hershman JM, et al., editors. Endotext. Massachusetts: South Dartmouth (MA); 2000.

16. Groat RA. Formation and growth of adrenocortical-like tissue in the ovaries of the adrenalectomized ground squirrel. The Anatomical Record 1944;89:33-41. 